\title{
Efectos jurídicos de la resistencia social a la legislación de asilo y refugio: el movimiento Sanctuary y la enmienda Boland ${ }^{1}$
}

\section{Legal Effects of Social Resistance to Asylum and Refugee Legislation: The Sanctuary Movement and the Boland Amendment}

\author{
Leandro Martínez Peñas ${ }^{2}$ \\ Universidad Rey Juan Carlos (España) \\ ORCID: https://orcid.org/0000-0001-7067-5589
}

Recibido: 29-06-2021

Aceptado: 16-09-2021

\section{Resumen}

La crisis migratoria desatada por el conflicto nicaragüense durante la presidencia Reagan tuvo importantes consecuencias sociales, con el movimiento Sanctuary, y legales, con la aprobación de la Enmienda Boland, que llevaría al escándalo Irán-Contra.

Palabras-clave: Reagan, Inmigración, Nicaragua, Enmienda Boland, Sanctuary.

\footnotetext{
${ }^{1}$ Este artículo se ha elaborado en el marco de dos proyectos: Proyecto "Integración, derechos humanos y ciudadanía global", dentro de la Convocatoria Pública de Subvenciones para Proyectos de Cooperación Internacional al Desarrollo, ejercicio 2020, financiada por el Ayuntamiento de Madrid, con una duración 1 de enero de 2020 a 31 de diciembre de 2021; y como una acción financiada por la Comunidad de Madrid en el marco del Convenio Plurianual con la Universidad Rey Juan Carlos en la línea de actuación 1, Programa de "Estímulo a la investigación de jóvenes doctores". Ref. proyecto V793, Acrónimo DEFSEG-GAMES, "Diseño, implementación y análisis de procesos gamificados y serious games para la consolidación de una cultura de democrática de Seguridad y Defensa".

2 (leandro.martinez@urjc.es) Profesor Titular de Historia del Derecho en la URJC, Académico Correspondiente de la Real Academia de Jurisprudencia y Legislación. Entre sus monografías cabe mencionar La guerra y el nacimiento del Estado Moderno (2014) y El Invierno. Visión jurídicoinstitucional de las relaciones internacionales en la Edad Media (2019
} 


\begin{abstract}
The migration crisis unleashed by the Nicaraguan conflict during the Reagan presidency had important social consequences, with the Sanctuary movement, and legal consequences, with the approval of the Boland Amendment, which would lead to the Iran-Contra scandal.
\end{abstract}

Keywords: Nicaragua, Reagan, Sanctuary Movement, Boland Amendment, Iran-Contra.

\title{
1. La cuestión centroamericana
}

Con la llegada a la presidencia de los Estados Unidos del republicano Ronald Reagan la Guerra Fría entró en una fase, que, a la postre, terminaría conduciendo a su final. El antiguo actor -que había compartido pantalla con Errol Flynn en Camino de Santa Fe-subiría la tensión del enfrentamiento con la Unión Soviética impulsando un gran aumento del gasto militar-que, combinado con un recorte impositivo de gran alcance acabaría llevando a un gargantuesco déficit público, que Estados Unidos arrastra hasta el día de hoy como uno de sus principales problemas-, una agresiva política de declaraciones públicas -a la que se ha dado el expresivo nombre de "diplomacia del megáfono" y que llegó a su punto culminante cuando, en Orlando, Reagan declaró que la URSS era un verdadero "imperio del mal"- y, finalmente, mediante la denominada Doctrina Reagan: el compromiso de ofrecer ayuda militar a aquellos que lucharan contra el comunismo en cualquier lugar del mundo.

Fue la Doctrina Reagan lo que llevó a que este apoyara, de forma algo irresponsable, como demostrarían los trágicos acontecimientos posteriores, a la insurgencia afgana contra el gobierno comunista respaldado por las tropas soviéticas $^{3}$ y, de la misma forma, fue la Doctrina Reagan lo que llevó a Estados Unidos a apoyar a los movimientos anticomunistas en Centroamérica, en su doble vertiente: gobiernos autoritarios -por lo general en manos de juntas militares- que luchaban contra insurgencias comunistas, como fueron los casos de El Salvador y de Honduras, o movimientos insurgentes que combatían a gobiernos socialistas o próximos a lo modelos soviéticos, como era el caso de la Contra nicaragüense, enfrentada al gobierno sandinista que había derrocado a los Somoza en $1979^{4}$.

\footnotetext{
3 Una reflexión sobre la deriva actual de la insurgencia afgana puede verse en el artículo de Sara Arrazola en Varios Autores, Contrainsurgencia y orden público: Aproximaciones hispánicas y globales. Valladolid, Veritas, 2020.

${ }^{4}$ En el caso concreto del sandinismo, junto a la ideología de corte socialista había una importante influencia de las corrientes católicas, como muestra que tres de los ministros sandinistas eran sacerdotes: Miguel d'Escoto, Fernando Cardenal - ambos jesuitas- y el hermano de este último, Ernesto, perteneciente a la Societas de Maryknoll pro missionibus exteris. Fueron responsables de las carteras de Asuntos Exteriores, Educación y Cultura, respectivamente (James Carroll, La casa de la 
Los movimientos de corte revolucionario habían encontrado su caldo de cultivo en la devastadora situación económico-social de Centroamérica a finales de los años setenta y comienzos de la década de 1980. Varias generaciones de extensiones de los monocultivos en manos de empresas norteamericanas como United Fruit o Domino Sugar habían terminado por llevar a que dos tercios de la población de América Central viviera por debajo del umbral de la pobreza, mientras que una élite del 5\% vivía en la opulencia ${ }^{5}$. La llegada del sandinismo al poder en Nicaragua coincidió con la de Reagan a la Casa Blanca, que, de inmediato, adoptó una postura beligerante contra el nuevo régimen, al que se consideró una amenaza para los intereses estadounidenses, tanto desde el punto de vista económico como, sobre todo, geoestratégico.

En este último sentido, se temía que Nicaragua se convirtiera en un foco de irradiación del socialismo revolucionario, como había ocurrido con la Cuba castrista en décadas anteriores. A fin de prevenir que algo así tuviera lugar, la Casa Blanca envió asesores y ayuda militar a los gobiernos autoritarios de El Salvador, Honduras y Guatemala y, sobre todo, comenzó a canalizarse una significativa cantidad de ayuda militar hacia la Contra nicaragüense, el movimiento guerrillero que trataba de derrocar a los sandinistas mediante la lucha $\operatorname{armada}^{6}$. Los gobiernos militares centroamericanos, que a comienzos de la década ya tenían a sus espaldas un triste saldo de más de cien mil víctimas mortales de su represión ${ }^{7}$, aumentaron la intensidad de esta ante el respaldo y la colaboración estadounidense, que incluyó la formación de muchos de sus oficiales en técnicas de interrogatorio en la tristemente célebre Escuela de las Américas ${ }^{8}$.

Las dictaduras centroamericanas, sintiéndose plenamente respaldadas por el gigante del Norte, se sintieron libres para prescindir de todo límite. Un ejemplo de ello lo constituye el asesinato, el 24 de marzo de 1980, del arzobispo de El Salvador, Óscar Romero, mientras celebraba misa. Su muerte tuvo lugar tan solo un día después de que declarara públicamente, en una alocución destinada a los soldados salvadoreños: "Estáis matando a vuestros

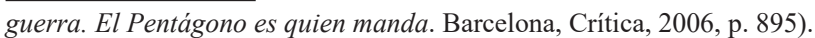

${ }^{5}$ Carroll, La casa de la guerra. El Pentágono es quien manda, p. 605.

${ }^{6}$ El presidente Reagan, durante una cena de recaudación de fondos celebrada el 1 de marzo de 1985, llegó a comparar a los contras con los revolucionarios norteamericanos y franceses del siglo XVIII.

7 Renny Golden y Michael McConnell, Sanctuary: The New Underground Railroad. Nueva York, Orbis Books, 1986, p. 20. En particular, en El Salvador existía una larga tradición de represión cruenta de la oposición social o política, como mostraba el precedente de "la Matanza", como se conoce a la represión desencadenada en la década de 1930 por el general Maximiliano Hernández Martínez contra las comunidades indígenas, y que se saldó con más de 30.000 muertos (Erik Ching, Authoritarian El Salvador: Politics and the Origins of the Military Regimes, 1880-1940. Notre Dame, University of Notre Dame Press, 2014, p. 257).

${ }^{8}$ Esta institución estaba ubicada en Fort Benning, el mismo acuartelamiento que aloja a las Fuerzas Especiales de los Estados Unidos.

Araucaria. Revista Iberoamericana de Filosofia, Política, Humanidades y Relaciones Internacionales, año $23, \mathrm{n}^{\circ} 48$. Tercer cuatrimestre de 2021. Pp. 493-511. ISSN 1575-6823 e-ISSN 2340-2199 https://dx.doi.org/10.12795/araucaria.2021.i48.22 
propios hermanos campesinos. Ningún soldado está obligado a obedecer una orden que vaya contra la ley de Dios".

La violencia contra aquellos miembros de la Iglesia que habían tomado sobre sus hombros la responsabilidad de alzar la voz contra la violencia del gobierno continuó. El 2 de diciembre de 1980, tres monjas y una religiosa laica fueron violadas y asesinadas por paramilitares de extrema derecha. En un intento de restar importancia a los crímenes cometidos por un gobierno al que Estados Unidos respaldaba, la embajadora estadounidense ante las Naciones Unidas, Jeanne Kirkpatrick declaró ante el Congreso que las fallecidas "no eran verdaderas monjas" ${ }^{10}$. Dos de las víctimas pertenecían a la Societas de Maryknoll pro missionibus exteris - conocida comúnmente como Orden de Maryknoll-, una institución creada en 1910 con el fin de enviar misioneros a aquellos lugares del mundo donde fueran más necesarios, lo que provocó la lógica conmoción dentro de la institución. Esto llevó a que una de las hermanas de Maryknoll acudiera a su sobrino, el congresista demócrata Thomas "Tip" O'Neill, que llevó la cuestión centroamericana al Congreso y la convirtió en un caballo de batalla contra la administración Reagan, por respaldar a "saqueadores, asesinos y violadores"11.

Las consecuencias de este incremento de la violencia en la región fueron inmediatas: en 1980, primer año de mandato de Reagan, ya se produjo una primera oleada de inmigrantes salvadoreños a los Estados Unidos, que sumaría un total de 70.000 desplazados antes de que terminara el año ${ }^{12}$. El proceso no hizo sino aumentar de intensidad en los años sucesivos, hasta alcanzar un total de más de medio millón de inmigrantes centroamericanos desplazados a Estados Unidos, a través de México, para el año $1984^{13}$. Semejante aluvión de migrantes, en su inmensa mayoría ilegales, se convirtió en un problema para la administración Reagan, a medida que su presencia era cada vez más notoria en las ciudades estadounidenses. Aunque muchos de ellos solicitaron asilo como

\footnotetext{
${ }^{9}$ Citado en Jonathan Kwitny, Man of the Century. Nueva York, 1997, Henry Holt and Company.

${ }^{10}$ Carroll, La casa de la guerra. El Pentágono es quien manda, p. 608. Kirkpatrick, antes de acceder a su cargo, había escrito un artículo titulado "Dictatorships and double Standards" (Commentary, $\mathrm{n}^{\circ}$ $23,1980)$, en el que afirmaba que había sido un grave error no apoyar a Somoza para que retuviera el poder, habida cuenta de que era un aliado de los Estados Unidos.

11 John A. Farrell, Tip O'Neil and the Democratic Century. Nueva York, 2001, Little Brown, p. 291.

12 Sobre la relación entre inmigración y la política internacional, ver Christopher Mitchell., "International Migration, International Relations and Foreign Policy", International Migration Review $\mathrm{n}^{\circ} 23,1989$, pp. 681-708. Una perspectiva histórica sobre los refugiados puede verse en Erika Prado Rubio, "La regulación del estatuto jurídico de los expatriados receptores de un pasaporte Nansen (1922-1928)", en prensa.

13 Walter LaFeber, America, Russia and the Cold War, 1945-2000. Nueva York, W. W. Walton\&Company, 2002, p. 142. Aproximadamente, 350.000 de ellos procedían de El Salvador (America's Watch, Report on Human Rights in El Salvador: Compiled by Americas Watch and the American Civil Liberties Union. Nueva York, America's Watch,1982, p. xxviii), lo cual suponía una cuarta parte de la población total del país (UNHCR, UNHCR Information Paper: International Conference on Central American Refugees, Guatemala, UNHCR, 1989).
} 
refugiados políticos, el gobierno rechazó la gran mayoría de las peticiones de forma: en 1981, solo dos de los más de 5.000 salvadoreños que solicitaron asilo legalmente vieron aceptada su petición; entre 1983 y 1986, se concedió asilo al 2,3\% de los solicitantes salvadoreños y al $0,9 \%$ de los solicitantes guatemaltecos, unas cifras que estaban muy por debajo del 14\% de aceptación media sobre el total de las solicitudes de asilo recibidas en Estados Unidos ${ }^{14}$.

La razón de esta negativa sistemática a conceder el estatus de refugiado a los centroamericanos era una cuestión de estricta política internacional: admitir que los salvadoreños, hondureños o guatemaltecos que huían de la represión en sus países de origen eran refugiados políticos era admitir la ilegitimidad y la condición antidemocrática de sus gobiernos, a los que la administración Reagan apoyaba intensamente ${ }^{15}$. Dicho de otra forma, era reconocer explícitamente que Estados Unidos estaba apoyando a dictaduras.

Las consideraciones derivadas de la Guerra Fría marcaron la política de inmigración norteamericana entre 1950 y $1990^{16}$, algo particularmente evidente en el caso de la crisis de los refugiados centroamericanos. Esto era posible debido a que la ley de refugiados en vigor en Estados Unidos en aquel momento, que databa de 1980, si bien había sido un notable paso a crear un procedimiento estandarizado acorde con la legislación internacional sobre la materia, también dejaba un espacio para su orientación conforme a criterios políticos, creando la figura del Coordinador para los Refugiados dentro del Departamento de Estado - esto es, el ministerio de Asuntos Exteriores- y estableciendo que si bien el Congreso podía ser consultado en materia de asilo, su parecer era meramente consultivo $^{17}$.

La inmensa mayoría de los migrantes salvadoreños, hondureños y guatemaltecos fueron considerados migrantes por motivos económicos, no elegibles para la condición de refugiado político, debido a que los migrantes económicos se consideraban desplazados voluntarios y, según la normativa de Naciones Unidas, era condición indispensable del refugiado político el que su emigración hubiera sido forzosa, para salvaguardar su vida o su libertad ${ }^{18}$.

${ }^{14}$ Norman L. Zucker y Naomi Funck Zucker, The Guarded Gate: The Reality of American Refugee Policy. San Diego, CRDH, 1987, p. 144. La legislación estadounidense no fijaba un tope anual que limitara el número de personas que podían ser aceptadas como refugiadas (Paul W. Schmidt, "Refuge in the United States: the sanctuary movement should use the legal system", Hofstral Law Review, $\mathrm{n}^{\circ}$ 15, 1986, p. 80).

${ }^{15}$ Carroll, La casa de la guerra. El Pentágono es quien manda, p. 610; Stefon Andrews, Sanctuary and the Cold War: The US Versus The Sanctuary Movement in Texas and Arizona, 1981-1986. Dallas, Southern Methodist University, 2018, p. 10.

${ }^{16}$ David M., Reimers, Still the Golden Door: The Third World Comes To America. Nueva York, Columbia Press, 1985, p. 35.

17 Elisabeth G. Ferris, Central American Refugees and the Politics of Protection. Nueva York, Praeger, 1987, p. 113.

${ }^{18}$ Louis W. Holbourn, Refugees: A Problem of Our Time. The Work of the United Nations High Commissioner for Refugees. Metuchen, Scarecrow Press, 1975, vol. I, p. 89. 
Existían precedentes en la actuación de Estados Unidos en los que, de forma excepcional, se concedía el asilo a refugiados voluntarios procedentes de países concretos. Así se había hecho en los años previos, estableciendo excepciones para los nacionales de Polonia, Afganistán y Etiopía, pero, en 1983, el Fiscal General de los Estados Unidos William French Smith rechazó extender esta consideración a los salvadoreños ${ }^{19}$.

Con semejante marco político, el Servicio de Inmigración estadounidense comenzó a deportar a millares de refugiados centroamericanos a sus países de origen, entregándolos a las autoridades de las que habían tratado de huir y condenando a muchos de ellos a un destino ciertamente trágico ${ }^{20}$.

\section{Acogerse a sagrado}

La política de deportaciones aplicada a los migrantes centroamericanos que huían de la represión en sus países de origen provocó una reacción a gran escala en el seno de la comunidad católica, muy sensibilizada por el asesinato de Romero y de las religiosas violadas en diciembre de 1980, y que había encontrado eco congresual en la persona del congresista $\mathrm{O}^{\prime} \mathrm{Neill}$.

La forma en que se canalizó esta reacción del catolicismo fue realmente llamativa desde el punto de vista jurídico. Todo comenzó cuando Jim Dudley, un texano que regresaba a su país a través de la frontera de México, recogió justo al norte de la demarcación a un inmigrante salvadoreño, al cual entregó a la Patrulla de Fronteras cuando esta detuvo su vehículo ${ }^{21}$. Dudley comentó el incidente a Jim Corbett, uno de sus vecinos, cuáquero, que comenzó a interesarse por la suerte de aquel hombre y las circunstancias que lo habían llevado a terminar en un centro de detención del Servicio de Inmigración ${ }^{22}$. Al tratar de brindar al detenido la asistencia legal que la legislación le reconocía ${ }^{23}$, el texano se encontró con todo tipo de problemas burocráticos y decidió

19 Schmidt, "Refuge in the United States: the sanctuary movement should use the legal system", p. 88.

${ }^{20}$ Las deportaciones habían sido ya la respuesta habitual del Servicio de Inmigración ante los refugiados llegados de Centroamérica en los años previos, pero dando prioridad a la llamada deportación voluntaria, por la cual el inmigrante indocumentado que era detenido en Estados Unidos podía aceptar voluntariamente su deportación sin esperar a que concluyera el proceso legal al respecto. La mayor parte de los migrantes aceptaban esta fórmula en los años previos a la crisis, debido a que los deportados forzosos no eran candidatos elegibles para obtener un visado de entrada legal en el futuro.

21 Beckemeyer, A., The Acme of the Catholic Left: Catholic Activists in the US Sanctuary Movement, 1982-1992. Detroit, Detroit Sanctuary Project Mailing, 2012, p. 1.

${ }^{22}$ Hillary Cunningham, God and Caesar at the Rio Grande: Sanctuary and the Politics of Religion. St.Paul, University of Minnesota, 1995, p. 23.

23 Teóricamente, quienes se enfrentaban al proceso de deportación recibían, de manos de las autoridades, un listado de organizaciones sin ánimo de lucro que brindaban asistencia jurídica a los solicitantes de asilo (Schmidt, "Refuge in the United States: the sanctuary movement should use the legal system", p. 84). 
comenzar una campaña para asistir a los refugiados, alojando en su rancho a cuántos podía, de forma que, en junio de 1981, ya había veintiún salvadoreños residiendo en su propiedad, y más aún fueron alojados con otros cuáqueros de la comunidad de Corbett.

El activismo de Corbett y la tragedia de Pipe Organ, en la que trece inmigrantes salvadoreños - de un total de veintisiete- perdieron la vida en el desierto tras cruzar la frontera de forma ilegal ${ }^{24}$ dieron relevancia social al problema de los inmigrantes y pronto el Concilio Ecuménico de Tucson, que agrupaba a sesenta y cinco congregaciones religiosas de Arizona, tanto católicas como protestantes, comenzó a recaudar fondos para ofrecer asistencia legal a los refugiados, siguiendo con la tradición de acogida a los refugiados que Arizona había mostrado a lo largo de la década previa, donde se significó por ofrecer un hogar a muchas personas que huían de los horrores de la dictadura chilena ${ }^{25}$. No obstante, los intentos legales de que los refugiados consiguieran asilo político toparon con la voluntad estratégica del gobierno de negarlo, y fue orientando a los activistas de Arizona cada vez más hacia prácticas al margen de la ley, comenzando a recoger a los migrantes antes de que la Patrulla de Fronteras los interceptara y llevándolos acto seguido a diversas instalaciones religiosas ${ }^{26}$. Una vez en ellas, se negaban a facilitar a las autoridades de inmigración el acceso a las mismas para procesar a los migrantes.

El 24 de marzo de 1980, el día en que se cumplían dos años del asesinato de monseñor Romero en San Salvador, la comunidad presbiteriana del pastor John Fife se declaró públicamente como un santuario donde se ofrecería el derecho de acogerse a sagrado a los inmigrantes centroamericanos ${ }^{27}$. Su ejemplo se extendió por Arizona y, más tarde, al resto del país. Ese mismo año, treinta entidades religiosas ubicadas a lo largo de todos los Estados Unidos -incluyendo sinagogas, iglesias, monasterios, conventos y escuelas-, declararon que ejercerían el derecho histórico del acogimiento a sagrado para con los inmigrantes centroamericanos en riesgo de ser deportados a sus países de origen.

La creación de santuarios, es decir, de espacios seguros para las personas en ellos refugiados, se remonta a la Antigüedad ${ }^{28}$, siendo muy habitual la

\footnotetext{
${ }^{24}$ Andrews, Sanctuary and the Cold War: The US Versus The Sanctuary Movement in Texas and Arizona, 1981-1986, p. 18.

${ }^{25}$ Cunningham, God and Caesar at the Rio Grande: Sanctuary and the Politics of Religion, p. 15. Sobre los orígenes de la violencia política en Chile, ver Manuela Fernández Rodríguez y Leandro Martínez Peñas, "Violencia y alteraciones políticas en el Chile decimonónico", en Revista electrónica Iberoamericana, $\mathrm{n}^{\circ}$ 16, 2010, 123-145.

${ }^{26}$ Stacy Lynn Merkt, "Conspiracy of Compassion: Four Indicted Leaders Discuss the Sanctuary Movement", Sojourners, n 14, 1985, pp. 14-18.

27 Andrews, Sanctuary and the Cold War: The US Versus The Sanctuary Movement in Texas and Arizona, 1981-1986, p. 19; Beckemeyer, The Acme of the Catholic Left: Catholic Activists in the US Sanctuary Movement, 1982-1992, p. 9.

${ }^{28}$ Varios Autores, "Interdisciplinary Approaches to Refugee and Migration Studies. Lessons from
} 
vinculación entre estos espacios seguros y las instituciones religiosas ${ }^{29}$. Algunos autores lo consideran una tradición legal de origen hebreo ${ }^{30}$, en la cual se acogía a los fugitivos de tal forma que quedaran a salvo de la aplicación de la ley del Talión por parte de los familiares de sus víctimas ${ }^{31}$, un elemento jurídico conocido como venganza de sangre ${ }^{32}$. En Occidente, el reconocimiento del derecho de acogerse a sagrado, es decir, que un presunto delincuente se refugiara en una iglesia, donde no podía ser detenido por las autoridades civiles, tomó forma a partir del año 600, y siguió vigente en algunas legislaciones europeas, como la inglesa, durante prácticamente un milenio ${ }^{33}$. El triunfo paulatino de los regímenes constitucionales y de las formas liberales de gobierno terminaron por suprimir el derecho de acogimiento a sagrado de la mayor parte de las legislaciones europeas ${ }^{34}$.

En el siglo XVI, Enrique VIII continuó la tradición inglesa convirtiendo un determinado número de ciudades en santuarios donde podían refugiarse los fugitivos sin temor a ser castigados por las autoridades. La medida fue sumamente impopular en las propias ciudades designadas, que veían en la medida una invitación a convertirse en refugio de criminales, en detrimento del común de sus habitantes ${ }^{35}$.

Históricamente, el derecho a acogerse a sagrado implicaba que las autoridades civiles no pueden penetrar en un recinto religioso para detener a aquellas personas que hayan reclamado el ejercicio de tal derecho. En la práctica de 1982, suponía que las comunidades religiosas negaban a las

Collaborative Research on Sanctuary in the Changing Times of Trump", Migration and Society: Advances in Research, $\mathrm{n}^{\mathrm{o}}$ 1, 2018, p. 165.

${ }^{29}$ Linda Rabben, Sanctuary and Asylum: A Social and Political History, Seattle, University of Washington Press, 2016, p. 34.

${ }^{30}$ Por ejemplo, Andrews, Sanctuary and the Cold War: The US Versus The Sanctuary Movement in Texas and Arizona, 1981-1986, p. 11.

31 Christine Goodall, "Sanctuary and solidarity: urban community responses to refugees and asylum seekers on three continents", New Issues in Refugee Research, n 221, 2011, p. 7.

${ }^{32}$ Schmidt, "Refuge in the United States: the sanctuary movement should use the legal system", p. 93.

${ }^{33}$ Karl Shoemaker, Sanctuary and Crime in the Middle Ages, 400-1500. Nueva York, Fordham University Press, 2011, p. 73. En el caso inglés, la tradición de acogerse a sagrado en una iglesia se aplicaba especialmente al delito de traición, que, con frecuencia, era fruto de persecuciones de índole política (Goodall, "Sanctuary and solidarity: urban community responses to refugees and asylum seekers on three continents", p. 8). La legislación inglesa abolió el derecho a sagrado en 1624 (Schmidt, "Refuge in the United States: the sanctuary movement should use the legal system", p. 94).

34 Varios Autores, "Interdisciplinary Approaches to Refugee and Migration Studies", p. 166. Sobre cómo se produjo este triunfo del liberalismo en España pueden verse los trabajos de Manuela Fernández Rodríguez, como El gobierno de los presidiarios, Valladolid, Veritas, en prensa; Hombres desleales cercaron mi lecho, Valladolid, Veritas, 2018; "Las tres Españas de 1808", Revista Aequitas, $n^{\circ}$ 13, 2018; "La construcción jurídico-institucional del ejecutivo de Evaristo Pérez de Castro: Fernando VII frente al gobierno", Revista Aequitas, n 16, 2020; y "Las reformas legislativas de marzo de 1820 y la recuperación del aparato normativo doceañista” [Enrique San Miguel Pérez, coord., En la Europa liberal: el trienio y el paraíso. Madrid, FUE, 2020].

35 Goodall, "Sanctuary and solidarity: urban community responses to refugees and asylum seekers on three continents", p. 8. 
autoridades de Inmigración el permiso para penetrar en los recintos de una iglesia para efectuar registros o detenciones, por lo que resultaba virtualmente imposible, en aplicación del acogimiento a sagrado, deportar a los salvadoreños, hondureños y guatemaltecos que se refugiaban en el interior de los recintos religiosos, convirtiéndose estos en auténticos santuarios para los migrantes, de dónde tomaría su nombre el movimiento -Sanctuary, es decir, "santuario" en lengua inglesa-.

Desde el punto de vista de la legislación internacional, Estados Unidos no tenía la obligación de conceder asilo a los refugiados centroamericanos, ya que el derecho de asilo, como tal, no existe ${ }^{36}$. En su lugar, la Declaración de Derechos Humanos incluye el derecho a buscar asilo, algo bien diferente, puesto que, si bien no puede impedirse a ninguna persona tratar de lograr asilo, es voluntad del Estado receptor el concederlo o no. Lo que sí establecía la Convención y el Protocolo de Naciones Unidos sobre el estatuto de los refugiados es que no se debía devolver a su Estado de origen a aquellas personas cuya vida peligrara en caso de que dicha devolución fuera llevada a cabo ${ }^{37}$. Sin embargo, para Estados Unidos, este principio no era aplicable al caso de los inmigrantes centroamericanos, debido a la consideración de refugiados económicos que les atribuía la administración Reagan.

En realidad, la reclamación del derecho a acogerse a sagrado que efectuaban los centros receptores carecía de valor legal, puesto que no figuraba en la legislación norteamericana, donde la única figura que podía conceder asilo legalmente era el Fiscal General de los Estados Unidos, en virtud de la Refugee Act of $1980^{38}$, norma que había actualizado la legislación migratoria estadounidense y la había aproximado a los parámetros internacionales ${ }^{39}$. De hecho, acoger u ocultar a un inmigrante indocumentado era un delito. Por ello, la actitud de las comunidades religiosas, más que el ejercicio de un verdadero derecho, era un acto de desobediencia civil.

Ayudado por la existencia de una larga tradición de desobediencia civil en la sociedad norteamericana ${ }^{40}$, desde la lucha de los abolicionistas, el Ferrocarril Subterráneo, el sufraguismo, la lucha por los derechos civiles o el mismo derecho de asilo que iglesias de San Francisco reclamaron de cara a los objetores que se negaban a ir a Vietnam ${ }^{41}$, el movimiento se extendió

\footnotetext{
${ }^{36}$ Guy S. Goodwin-Gill, "International Law and Human Rights: Trends Concerning International Migrants and Refugees", International Migration Review, n 23 , 1989, pp. 526-546.

${ }^{37}$ Schmidt, "Refuge in the United States: the sanctuary movement should use the legal system", p. 90.

${ }^{38}$ Schmidt, "Refuge in the United States: the sanctuary movement should use the legal system", p. 81,

${ }_{39}$ Andrews, Sanctuary and the Cold War: The US Versus The Sanctuary Movement in Texas and Arizona, p. 9.

${ }^{40}$ Schmidt, "Refuge in the United States: the sanctuary movement should use the legal system", p. 95 .

${ }^{41}$ Andrews, Sanctuary and the Cold War: The US Versus The Sanctuary Movement in Texas and
} 
como la pólvora por los Estados Unidos, de tal forma que en 1984 eran ya más de trescientas las instituciones religiosas que se habían unido al movimiento Sanctuary y habían declarado públicamente su voluntad de reconocer el derecho de acogerse a sagrado para los migrantes centroamericanos ${ }^{42}$. Por si esto fuera poco, múltiples confesiones dieron su respaldo al movimiento: los cuáqueros del Comité Americano de Servicio a los Amigos, los unitarios del Sínodo General de la Iglesia Unida de Cristo, los presbiterianos de la Asamblea General de la Iglesia Presbiteriana de Estados Unidos, los metodistas de las Iglesia Metodista Unida, los luteranos de la Asamblea General de la Iglesia Luterana Americana... ${ }^{43}$.

En los lugares que formaban la red del movimiento Sanctuary, se prestaba asistencia a los inmigrantes, facilitándoles comida, ropa, refugio y asistencia social en la medida en que cada comunidad podía hacerlo, de modo que la noción iba mucho más allá de la mera protección frente a las autoridades ${ }^{44}$.

Aunque, como se ha dicho, el derecho de acogerse a sagrado o de convertir una dependencia religiosa en un santuario carecía de existencia legal, lo cierto es que las autoridades norteamericanas no irrumpieron por la fuerza en ninguno de los lugares que se proclamaron santuario, y ningún inmigrante fue detenido dentro de los mismos. Sin duda, las autoridades temían las consecuencias políticas y de opinión pública que podían derivarse de irrumpir por la fuerza en un espacio de culto. Algunos de los activistas del proyecto sí fueron llevados a juicio entre los años 1984 y 1986, en lo que ha sido considerado, por lo general, un intento del gobierno de salvar las apariencias respecto del movimiento, de forma que no pareciera que era complaciente, al tiempo que no intervenía en los lugares que se habían adherido a él.

El primer arresto tuvo lugar a los dos años de iniciado el movimiento, en 1984, procesándose a once miembros en el que, a la postre, sería el mayor de los procesos contra miembros de Sanctuary, Estados Unidos contra Aguilar et al, que se sustanció en el noveno circuito judicial del estado de Arizona ${ }^{45}$. La propia identidad religiosa de los acusados mostraba el ecumenismo del movimiento: en el banquillo del noveno circuito se sentaron, hombro con hombro, cuáqueros

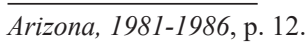

${ }^{42}$ En 1986, la cifra total era de 307 entidades (Sin Autor, Basta! National Newsletter of the Chicago Religious Task Force on Central America, de junio de 1986, p. 28).

${ }_{43}$ Carroll, La casa de la guerra. El Pentágono es quien manda, p. 897. Más adelante, incluso las comunidades nativas americanas se incorporaron para ofrecer santuarios, sobre todo, a los indígenas guatemaltecos, en cuyas tierras en Guatemala la guerrilla se había especialmente fuerte y por lo que sufrieron con especial saña la represión de la dictadura de García Lucas (Golden y McConnell, Sanctuary: The New Underground Railroad, p. 60).

${ }^{44}$ American Friends Service Committee, Seeking Safe Haven: A Congregational Guide to helping Central American Refugees in thUnited States. Nueva York, American Friends Service Committee, 1984, pp. 37-40.

${ }^{45}$ Zucker y Zucker, The Guarded Gate: The Reality of American Refugee Policy, p. 256. 
-incluyendo al propio Jim Corbett-, presbiterianos, metodistas, católicos y unitarios ${ }^{46}$.

Las acusaciones, complementadas con la deportación de cientos de emigrantes ${ }^{47}$, fueron fruto de la intervención de agentes del Servicio de Inmigración infiltrados en el movimiento. Los activistas fueron acusados de violación de las leyes de inmigración estadounidenses ${ }^{48}$, declarando el fiscal que el cumplimiento de la ley se encontraba por encima de las consideraciones relacionadas con la moral religiosa ${ }^{49}$. Por su parte, los acusados se declararon inocentes, alegando que sus acciones habían sido acordes al espíritu de la legislación tanto estadounidense como internacional, pues se orientaban a la consecución de un bien superior al derivado de la aplicación literal de la norma. El tribunal declaró culpables a nueve de los once acusados, pero ninguno de ellos llegó a entrar en prisión: fueron puestos en libertad provisional, pese a que las penas a las que algunos de ellos fueron sentenciados llegaban a los veinticinco años de cárcel.

Tras el proceso de Tucson, el movimiento incorporó la noción de "iniciativa civil", según la cual, los ciudadanos estaban legitimados a cumplir las normas internacionales -en este caso, brindar asilo a los refugiados- aún si el gobierno de los Estados Unidos estaba violándolas, según sostenía Sanctuary que estaba ocurriendo ${ }^{50}$. Aunque tal idea fue rechazada por los tribunales, abrió un debate de fondo sobre la preeminencia de la ley sobre los deberes de los ciudadanos y la obligación, tanto legal como moral, de cumplir o no leyes que son consideradas inmorales.

En 1987, el Tribunal Supremo de los Estados dio la razón al movimiento, al establecer que los refugiados y solicitantes de asilo que procedieran de países en guerra debían recibir, cuando menos, asilo temporal, rechazando las interpretaciones restrictivas llevadas a cabo por el Servicio de Inmigración en base a un precedente, el caso del Servicio de Inmigración contra CardozaFonseca. La base de la decisión del Tribunal fue considerar la existencia de guerra en el país de origen prueba de la denominada "presunción suficiente de persecución”, que tanto la ONU como Estados Unidos exigían para poder acceder al estatus de refugiado.

${ }^{46}$ Beckemeyer, The Acme of the Catholic Left: Catholic Activists in the US Sanctuary Movement, 1982-1992, p. 4.

${ }^{47}$ Andrews, S., Sanctuary and the Cold War: The US Versus The Sanctuary Movement in Texas and Arizona, 1981-1986. Dallas, 2018, p. 2.

${ }^{48}$ El proceso es analizado en detalle en David Matas, The Sanctuary Trial. Winnipeg, University of Manitoba, 1989.

${ }^{49}$ La investigación sobre la red de Tucson había sido impulsada por el fiscal Jim Rayburn, un feroz anticomunista que había servido en Vietnam, donde fue capturado por el enemigo y sufrió todo tipo de maltrato antes de lograr evadirse y regresar a territorio amigo a travesando la jungla. Rayburn estaba convencido de que los integrantes de Sactuary eran marxistas radicales y representaban un peligro para su país (Andrews, Sanctuary and the Cold War: The US Versus The Sanctuary Movement in Texas and Arizona, 1981-1986, p. 22).

${ }^{50}$ Corbett, "Foundations for the Future: An Interview with Jim Corbett", p. 30. 
Del movimiento Sanctuary derivó la campaña del Juramento de Resistencia. El término inglés, Pledge of Resistance, fue concebido como un desafío al Pledge of Alliance, o juramento de lealtad que cada mañana es recitado por los niños norteamericanos en las escuelas públicas de todos los Estados Unidos. Más de 70.000 personas, en el marco de la campaña, prestaron juramente de realizar actos de desobediencia civil con relación a la política estadounidense en Centroamérica ${ }^{51}$. La conjunción de Sanctuary y de Pledge of Resistance dio voz a la oposición moral de una parte importante de la sociedad norteamericana frente a la política exterior de su propio gobierno ${ }^{52}$, sacudiendo al país a través de un movimiento de base, completamente descentralizado y en el que las altas jerarquías eclesiásticas no jugaron un papel director ${ }^{53}$.

\section{La Enmienda Boland}

La presión social, canalizada a través de movimientos como Sanctuary y Pledge of Resistance, combinada con la presión política encabezada en el Congreso por Tip O'Neill, acabaron llevando a la aprobación de la Enmienda Boland, que impedía que se destinaran, de forma legal, fondos federales para financiar las actividades contrainsurgentes de los gobiernos de Honduras, El Salvador y Guatemala, así como las actividades insurgentes de la Contra en Nicaragua.

En realidad, la Enmienda Boland era un conjunto de tres enmiendas diferentes, si bien idénticas desde el punto de vista de su finalidad y contenido, aprobadas entre 1983 y 1984. Toman su nombre del senador demócrata Edward Boland, que presentó la primera de ellas el 8 de diciembre de 1983 y que, tras ser aprobada por el contundente balance de 411 votos a favor y ninguno en contra, fue firmada por el presidente Reagan el 21 de diciembre de 1982.

Se trataba de una coda a la Defense Appropriations Act of 1983, la norma que regulaba el presupuesto de gastos de Defensa, que prohibía que ninguna agencia federal -descripción que tenía claramente a la CIA como destinatariautilizara fondos estadounidenses de forma encubierta para financiar las actividades de la Contra en Nicaragua. La norma, un acuerdo de compromiso, se redactó en un lenguaje intencionadamente ambiguo, lo que permitió que fuera aceptable para demócratas y republicanos ${ }^{54}$. En un primer momento, el gobierno de Reagan optó por ceñirse a la letra de la norma para circunvalar su

${ }^{51}$ Carroll, La casa de la guerra. El Pentágono es quien manda, p. 611.

${ }^{52}$ Varios Autores., "Interdisciplinary Approaches to Refugee and Migration", p. 166.

${ }_{53}$ Barbara M., Yarnold, "The Role of Religious Organizations in the U.S. Sanctuary Movement" [Barbara Yarnold, editora, The Role of Religious Organizations in Social Movements, Nueva York, Praeger, 1991, p. 32.

54 Bretton G. Schiarioni, "Boland in the Wind: The Iran-Contra Affair and the Invitation to Struggle", Piperdine Law Review, no 17, 1990, p. 383.

Araucaria. Revista Iberoamericana de Filosofia, Politica, Humanidades y Relaciones Internacionales, año $23, \mathrm{n}^{\circ} 48$. Tercer cuatrimestre de 2021. Pp. 493-511. ISSN 1575-6823 e-ISSN 2340-2199 https://dx.doi.org/10.12795/araucaria.2021.i48.22 
fondo: en efecto, la CIA dejó de financiar las operaciones de la Contra, pero su lugar fue tomado por el Consejo de Seguridad Nacional, que, tal y como señaló un informe jurídico encargado al respecto por la administración Reagan, no tenía la consideración institucional de agencia y, por tanto, no veía su actividad constreñida por la Enmienda Boland, a la que, desde algunos círculos próximos al gobierno ${ }^{55}$, se llegó a tildar de inconstitucional, entendiendo que se trataba de un atentado contra la separación de poderes, al suponer una injerencia del legislativo en la actuación del ejecutivo ${ }^{56}$.

El propio Boland protestó, declarando que la voluntad del legislador estaba clara, y no era otra que poner fin al apoyo estadounidense a la Contra, por lo que cualquier interpretación que permitiera continuar dicho apoyo iba en contra del espíritu de la ley, si no de su forma ${ }^{57}$. Habida cuenta de que esta alegación no fue tomada en consideración por el gobierno, el legislativo fue más allá en su respuesta y modificó el texto de la Enmienda, que pasó a prohibir cualquier financiación de operaciones subversivas o paramilitares por parte del gobierno de los Estados Unidos con relación a la guerra en Nicaragua ${ }^{58}$, incluyendo la prohibición de actividades que pudieran suponer un intercambio de material estadounidense entre el gobierno derechista de Honduras y la Contra ${ }^{59}$, y que fue siendo renovada en 1983, 1984 y 1985, en cada caso con efectos sobre el siguiente año fiscal.

La Enmienda Boland era un duro varapalo no solo para el gobierno de Reagan, sino para su concepción de la geopolítica exterior, hasta el punto de que la administración decidió sortear los límites legales y seguir financiando, en la medida de lo posible, a la Contra. Para ello se urdió un complejo plan, que acabaría conociéndose como Irán-Contra. Un miembro del Consejo de Seguridad Nacional, Robert McFarlane ${ }^{60}$, y uno de los oficiales más condecorados del cuerpo de Marines en aquel momento, el teniente coronel Oliver North ${ }^{61}$, diseñaron una estrategia, que fue aprobada por las autoridades el 7 de diciembre de $1984^{62}$.

\footnotetext{
55 Schiarioni, "Boland in the Wind: The Iran-Contra Affair and the Invitation to Struggle", p. 384.

${ }^{56}$ Lo cierto es que ni siquiera los más críticos con la Enmienda Boland llevaron a esta ante el Tribunal Supremo para que decidiera sobre su supuesta inconstitucionalidad.

57 Schiarioni, "Boland in the Wind: The Iran-Contra Affair and the Invitation to Struggle", p. 390.

58 Theodor Draper, A Very Thin Line: The Iran-Contra Affair. Nueva York, Shadows Books, pp. $17-27$ y p. 51.

${ }^{59}$ Louis Fisher, "Investigating Iran-Contra”, en VV. AA., The Constitution Project, Washington, Library of Congress, p. 275.

${ }^{60}$ McFarlane, antiguo marine, poseía una amplia experiencia en los círculos decisorios de la Casa Blanca, ya que había sido el asesor militar de Henry Kissinger -a quien acompañó en su histórica visita a China- dentro del Consejo de Seguridad Nacional durante parte del tiempo que Kissinger fue secretario de Estado, y el propio Reagan lo designó en 1983 como su representante en las negociaciones relativas a la paz en Oriente Medio.

${ }^{61}$ North había sido jefe de sección en Vietnam, donde había ganado en combate una Estrella de Plata, una Estrella de Bronce y recibido dos Corazones Púrpura, medalla que se entrega a aquellos que resultan heridos en acto de servicio. Fue incorporado al Consejo de Seguridad Nacional por la administración Reagan.

${ }^{62}$ Carroll, La casa de la guerra. El Pentágono es quien manda, p. 612.
} 
En aquel momento, la guerra civil libanesa se encontraba en su apogeo, y uno de sus actores más destacados, la organización chií Hezbollah, respaldada por Irán ${ }^{63}$, había hecho del secuestro y, llegado el caso, asesinato, de rehenes norteamericanos una baza estratégica de primer orden para tratar de influir sobre las políticas estadounidenses en la región. El plan diseñado por North y McFarlane consistía en vender en secreto armamento estadounidense a Irán -donde la revolución islámica de Jomeini había derribado al sha, aliado de los norteamericanos, en 1979-, a cambió de que Hezbollah, que dependía estrechamente de las autoridades de Teherán, liberara a varios de los rehenes que tenía en su poder ${ }^{64}$. Como se trataba de una venta secreta de armas, el dinero que los iraníes pagarían por el armamento estadounidense escaparía, al menos en teoría, de todo control público, lo que permitiría desviar al menos una parte y canalizarlo hasta la Contra nicaragüense, para que pudiera seguir financiando su guerra contra los sandinistas.

Sin embargo, el Irán-Contra apenas pudo permanecer poco más de un año en secreto. El 5 de octubre, un avión repleto de material militar y perteneciente a una compañía fantasma propiedad de la CIA fue derribado sobre Nicaragua. Su piloto, Eugene Hasenfus, fue capturado con vida por los sandinistas ${ }^{65}$. Aunque el gobierno de Estados Unidos negó todo conocimiento de los hechos, el 3 de noviembre el periódico libanés de alineamiento pro-sirio, Al Shiraa publicó que los estadounidenses estaban vendiendo armas a Irán en secreto ${ }^{66}$, algo que fue confirmado acto seguido por el propio gobierno iraní ${ }^{67}$. El escándalo escaló hasta el punto de que pronto fue evidente que el propio presidente era conocedor de las operaciones realizadas por North y el resto de implicados. La imagen pública y la popularidad del presidente terminaron tremendamente dañada, y muchos de los asesores que habían tomado participación directa en el Irán-Contra fueron juzgados y encarcelados, entre ellos Oliver North, si bien el veredicto condenatorio fue anulado en $1991^{68}$.

${ }^{63}$ Hezbollah había nacido como una escisión radical del movimiento chí libanés Amal, respaldado por Siria.

${ }^{64}$ North conocía de primera mano el conflicto libanés, ya que había liderado los esfuerzos norteamericanos por capturar a los responsables del atentado de Beirut del 23 de octubre de 1983, que causó la muerte a 243 militares estadounidenses.

${ }^{65}$ Fischer, "Investigating Iran-Contra", p. 277.

${ }^{66}$ Schiaroni, "Boland in the Wind: The Iran-Contra Affair and the Invitation to Struggle", p. 379.

${ }^{67}$ Fisher, "Investigating Iran-Contra", p. 277.

${ }_{68}$ McFarlen, por su parte, intentó suicidarse antes de prestar declaración ante el Congreso, y terminó siendo condenado por su implicación en el Irán-Contra, si bien fue indultado por el presidente George Bush -vicepresidente de Reagan en el momento en que se gestó la operación- el día de Navidad de 1992. 


\section{Conclusiones}

Quizá el mayor triunfo legislativo para los defensores de los refugiados se produjo cuando, en 1990, el Congreso estadounidense concedió el Temporary Protected Status (TPS) para los emigrantes salvadoreños y guatemaltecos. Esta medida suponía se concedían dieciocho meses de residencia legal en los Estados Unidos a todo inmigrante de dicha procedencia que hubiera entrado al país antes del 19 de septiembre de 1990, con independencia de si lo había hecho de forma legal o ilegal ${ }^{69}$.

El movimiento Santuario declinó durante la década de 1990, pero resurgió de las cenizas a partir de 2010, cuando el gobierno demócrata de Barack Obama comenzó a deportar a miles de inmigrantes ilegales y rebrotaría aún con más fuerza durante el mandato del cuadragésimo quinto presidente de los Estados Unidos, el republicano Donald Trump ${ }^{70}$. La revisión que ha suscitado este renacer ha llevado a interpretaciones muy variadas, incluyendo algunas que consideran que, en realidad, Sanctuary fracasó en su propósito de movilizar el sentimiento religioso en favor de los emigrantes salvadoreños, ya que, si bien 462 instituciones religiosas se adhirieron, en un momento u otro, al movimiento $^{71}$, otras 10.000 no lo hicieron ${ }^{72}$.

La fuerza del movimiento derivó de la solidez del convencimiento de sus miembros en el valor moral de lo que estaban haciendo, en base a dos argumentarios diferentes. Por un lado, la creencia de que sus actos eran acordes con la legalidad internacional, siendo el gobierno de Reagan quien se había apartado de dicha legalidad; por otro, que la actuación de Sanctuary respondía a una obligación moral de carácter religioso -llámese caridad, solidaridad, justicia social o servicio al prójimo- que debía cumplirse mediante una expresión de carácter político, pero no politizada. Esto último fue uno de los grandes éxitos del movimiento: votantes republicanos y demócratas formaron parte del mismo, sin que sus diferencias políticas importaran lo más mínimo, de igual modo que no había importado la confesión a la hora de integrar a católicos, luteranos, unitarios, metodistas, presbiterianos, cuáqueros, judíos e incluso nativos americanos en el paraguas conjunto de Sanctuary. Otro de los elementos clave en el éxito del movimiento fue que, quienes lo pusieron en marcha y lo integraron, por lo general se encontraban fuera de los círculos del

69 Serin Houston y Charlotte Morse, "The Ordinary and Extraordinary: Producing Migrant Inclusion and Exclusion in US Sanctuary Movements", Studies in Social Justice, n 11, 2017, p. 31.

${ }^{70}$ Varios Autores, "Interdisciplinary Approaches to Refugee and Migration Studies", p. 166. Ver, al respecto, Rose Cuison Villazor y Pratheepan Gulasekaram, "Sanctuary Networks", Minnesota Law Review, $\mathrm{n}^{\circ} 103,2019$.

71 Beckemeyer, The Acme of the Catholic Left: Catholic Activists in the US Sanctuary Movement, 1982-1992, p. 8; de ellas, 78 pertenecían a la Iglesia católica.

72 Andrews, Sanctuary and the Cold War: The US Versus The Sanctuary Movement in Texas and Arizona, 1981-1986, p. 13.

Araucaria. Revista Iberoamericana de Filosofí, Política, Humanidades y Relaciones Internacionales, año $23, \mathrm{n}^{\circ} 48$. Tercer cuatrimestre de 2021. Pp. 493-511. ISSN 1575-6823 e-ISSN 2340-2199 https://dx.doi.org/10.12795/araucaria.2021.i48.22 
activismo político: eran gente corriente a quienes la situación de los migrantes centroamericanos en Estados Unidos les parecía injusta e inmoral.

Las implicaciones que Sanctuary tuvo sobre la política exterior norteamericana fueron de largo alcance. El movimiento trajo a primera plana de la actualidad estadounidense no solo la crisis de los refugiados, sino las responsabilidades que se derivaban de la Doctrina Reagan, en base a la cual se estaba interviniendo en Centroamérica respaldando a gobiernos y movimientos insurgentes cuyas credenciales humanitarias y democráticas eran, en el mejor de los casos, muy dudosas. La Enmienda Boland supuso una limitación legal al desarrollo de este tipo de intervenciones encubiertas, generando los posteriores intentos de la administración Reagan de soslayar el cumplimiento de la norma, primero a través del Consejo de Seguridad Nacional y más tarde, cuando esa vía también se cerró, a través del desvío a la Contra de fondos procedentes de la venta secreta de armas a Irán, a cambio de la liberación de rehenes por Hezbollah, en una clara quiebra de la política oficial estadounidense, que declaraba a pleno pulmón que Estados Unidos no negociaría con los terroristas que retenían a sus ciudadanos en el Líbano.

El estallido del escándalo Irán-Contra dañó terriblemente al prestigio de Estados Unidos en la escena internacional, y deterioró la imagen pública del presidente Reagan, cuyo mandato quedó manchado de forma indeleble por el escándalo, una vez quedó demostrado más allá de toda duda que, pese a las vacilantes negativas del mandatario, el presidente había sido conocedor en todo momento de la operación.

Aunque "la historia de Sanctuary apenas se recuerda y es, por ende,

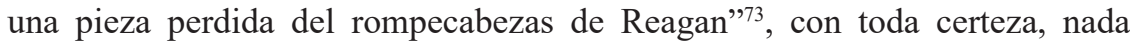
de lo anterior hubiera ocurrido de no ser por la iniciativa de un puñado de comunidades religiosas católicas, protestantes, judías y nativas americanas, que reclamaron de forma simbólica el ancestral derecho de acogimiento a sagrado como una forma de prestar auxilio a, en las imperecederas palabras de Emma Lazarus grabadas al pie de la Estatua de Libertad, los pobres, los cansados, los desheredados, "las innumerables masas que aspiran a vivir libres".

\section{Bibliografía:}

America's Watch, Report on Human Rights in El Salvador: Compiled by Americas Watch and the American Civil Liberties Union. Nueva York, America's Watch,1982.

\footnotetext{
${ }^{73}$ Carroll, La casa de la guerra. El Pentágono es quien manda, p. 605.
} 
American Friends Service Committee, Seeking Safe Haven: A Congregational Guide to helping Central American Refugees in thUnited States. Nueva York, American Friends Service Committee, 1984.

Andrew Beckemeyer, The Acme of the Catholic Left: Catholic Activists in the US Sanctuary Movement, 1982-1992. Detroit, Detroit Sanctuary Project Mailing, 2012.

Andrews, Stefon, Sanctuary and the Cold War: The US Versus The Sanctuary Movement in Texas and Arizona, 1981-1986. Dallas, Southern Methodist University, 2018.

Arrazola Ruiz, Sara: "Afganistán: un escenario complejo" [Varios Autores, Contrainsurgencia y orden público: Aproximaciones hispánicas y globales. Valladolid, Veritas y FUE, 2020].

Carroll, James, La casa de la guerra. El Pentágono es quien manda. Barcelona, Crítica, 2006, p. 895).

Ching, Erik, Authoritarian El Salvador: Politics and the Origins of the Military Regimes, 1880-1940. Notre Dame, University of Notre Dame Press, 2014. Cuison, Villazor, Rose; y Gulasekaram, Pratheepan, "Sanctuary Networks", Minnesota Law Review, n 103, 2019.

Cunningham, Hillary God and Caesar at the Rio Grande: Sanctuary and the Politics of Religion. St. Paul, University of Minnesota, 1995.

Draper, TheodorA Very Thin Line: The Iran-Contra Affair. Nueva York, Shadows Books.

Farrell, John A., Tip O'Neil and the Democratic Century. Nueva York, Little Brown, 2001.

Fernández Rodríguez, Manuela, "La construcción jurídico-institucional del ejecutivo de Evaristo Pérez de Castro: Fernando VII frente al gobierno”, Revista Aequitas, nº 16, 2020.

Fernández Rodríguez, Manuela, "Las reformas legislativas de marzo de 1820 y la recuperación del aparato normativo doceañista” [Enrique San Miguel Pérez, coord., En la Europa liberal: el trienio y el paraíso. Madrid, FUE, 2020].

Fernández Rodríguez, Manuela, "Las tres Españas de 1808”, Revista Aequitas, $n^{\circ} 13,2018$.

Fernández Rodríguez, Manuela, El gobierno de los presidiarios, Valladolid, Veritas, en prensa.

Fernández Rodríguez, Manuela, Hombres desleales cercaron mi lecho, Valladolid, Veritas, 2018.

Fernández Rodríguez, Manuela; y Martínez Peñas, Leandro, "Violencia y alteraciones políticas en el Chile decimonónico", Revista electrónica Iberoamericana, $\mathrm{n}^{\mathrm{o}} 16,2010$. 
Ferris, Elisabeth G., Central American Refugees and the Politics of Protection. Nueva York, Praeger, 1987.

Fisher, L., "Investigating Iran-Contra" [Varios Autores, The Constitution Project, Washington, Library of Congress, 2002].

Golden, Renny; McConnell, Michael, Sanctuary: The New Underground Railroad. Nueva York, Orbis Books, 1986.

Goodall, Christine, "Sanctuary and solidarity: urban community responses to refugees and asylum seekers on three continents", New Issues in Refugee Research, $\mathrm{n}^{\mathrm{o}} 221,2011$.

Goodwin-Gill, Guy, S., "International Law and Human Rights: Trends Concerning International Migrants and Refugees", International Migration Review, $\mathrm{n}^{\circ} 23,1989$.

Holbourn, Louis W., Refugees: A Problem of Our Time. The Work of the United Nations High Commissioner for Refugees. Metuchen, Scarecrow Press, 1975.

Houston, Serin; y Morse, Charlotte; "The Ordinary and Extraordinary: Producing Migrant Inclusion and Exclusion in US Sanctuary Movements", Studies in Social Justice, $\mathrm{n}^{\circ}$ 11, 2017.

Kwitny, Jonathan, Man of the Century. Nueva York, 1997, Henry Holt and Company.

LaFeber, Walter, America, Russia and the Cold War, 1945-2000. Nueva York, W. W. Walton\&Company, 2002.

Matas, David, The Sanctuary Trial. Winnipeg, University of Manitoba, 1989.

Merkt, Stacy Lynn, "Conspiracy of Compassion: Four Indicted Leaders Discuss the Sanctuary Movement", Sojourners, no 14, 1985.

Mitchell, Christopher, "International Migration, International Relations and Foreign Policy", International Migration Review no 23, 1989, pp. 681708.

Prado Rubio, Erika, "La regulación del estatuto jurídico de los expatriados receptores de un pasaporte Nansen (1922-1928)", en prensa.

Rabben, Linda, Sanctuary and Asylum: A Social and Political History, Seattle, University of Washington Press, 2016.

Reimers, David M., Still the Golden Door: The Third World Comes To America. Nueva York, Columbia Press, 1985.

Schiaroni, Bretton G., "Boland in the Wind: The Iran-Contra Affair and the Invitation to Struggle", Piperdine Law Review, n 17, 1990, p. 383.

Schmidt, Paul W., "Refuge in the United States: the sanctuary movement should use the legal system", Hofstral Law Review, n 15, 1986.

Sin Autor, Basta! National Newsletter of the Chicago Religious Task Force on Central America, de junio de 1986. 
UNHCR, UNHCR Information Paper: International Conference on Central American Refugees, Guatemala, UNHCR, 1989).

Varios Autores, "Interdisciplinary Approaches to Refugee and Migration Studies. Lessons from Collaborative Research on Sanctuary in the Changing Times of Trump", Migration and Society: Advances in Research, $\mathrm{n}^{\mathrm{o}} 1,2018$.

Yarnold, Barbara M., "The Role of Religious Organizations in the U.S. Sanctuary Movement" [Barbara Yarnold, editora, The Role of Religious Organizations in Social Movements, Nueva York, Praeger, 1991].

Zucker, Norman L., y Zucker, Naomi Funck, The Guarded Gate: The Reality of American Refugee Policy. San Diego, CRDH, 1987. 
